Maureen Sayres Van Niel, MD

President, American Psychiatric Association Women's

Caucus; Member, Steering Committee, US Dept of

HHS Women's Preventive Services Initiative, WPSI,

2016-2019; Reproductive Psychiatrist and Private

Consultant, Cambridge, MA
Jennifer L. Payne, MD

Associate Professor of Psychiatry \& Behavioral

Sciences and of Gynecology and Obstetrics; Director,

Women's Mood Disorders Center, The Johns Hopkins

University School of Medicine, Baltimore, MD

\title{
Perinatal depression: A review
}

\section{ABSTRACT}

Perinatal depression affects $10 \%$ to $20 \%$ of women in the United States during pregnancy, the postpartum period, or both, but it can be difficult to recognize. Identifying and treating this problem can reduce the alarming number of suicides among depressed perinatal women and the possible adverse effects of untreated maternal depression on their child's cognitive and behavioral development. In this review, we discuss the latest developments in screening, treatment, and prevention methods.

\section{KEY POINTS}

Screening for perinatal depression is recommended for all pregnant and postpartum women and is now a covered medical expense; the tools can be completed by patients in 2 minutes in the waiting room.

Perinatal depression can be prevented in some patients with regular counseling sessions.

Newly approved parenteral medications work immediately to ameliorate symptoms in moderate to severe disease.

Promising research suggests that we may be able to predict the likelihood of perinatal depression using biomarkers such as epigenetically modified genes.
Dr. Payne has disclosed membership on advisory committees or review panels for Janssen Pharmaceuticals Inc.

doi:10.3949/ccjm.87a.19054
EPRESSION is a COMMON medical condition in women during the perinatal period and is associated with serious consequences. It can cause intense sadness and anxiety in the mother and prevent her from bonding with or breastfeeding her baby. In severe cases, women may think about or actually harm themselves or their baby. Untreated perinatal depression in the mother can result in low birth weight and impaired social, cognitive, and emotional development in the baby.

Although it is imperative to recognize perinatal depression for these and other reasons, it is often overlooked in the primary care setting, especially since patients may be reluctant to reveal their symptoms. Therefore, many women with perinatal depression go undiagnosed, and even when it is detected, only some receive follow-up treatment. ${ }^{1}$

In this review, we discuss the latest methods for preventing, identifying, and treating perinatal depression.

\section{DEFINITION AND PRESENTATION}

Perinatal depression can occur during pregnancy (prenatally), the year following birth (postpartum), or both. Although feelings of weepiness and labile emotions, called the "baby blues," occur in up to $80 \%$ of new mothers within several days of delivery because of regulatory biochemical changes, these symptoms are usually brief and last no longer than 10 days. $^{2}$ Perinatal depression, on the other hand, lasts more than 14 days and impairs a woman's quality of life. Table 1 lists common symptoms.

\section{INCIDENCE, ETIOLOGY, AND RISK FACTORS}

The incidence of perinatal depressive disorder is surprisingly high in the United States. 


\section{TABLE 1}

\section{Common symptoms of perinatal depression}

Patients with perinatal depression may present with some or many of the following:

Sadness

Depressed mood and energy

Weepiness

Impaired appetite or overeating

Either excessive sleep or insomnia

Feelings of unworthiness

Anxiety

Panic attacks

Worrying constantly about the well-being of the baby, engaging in obsessive or ritualistic activities

Being afraid to leave the house

Feeling numb, wooden, and void of feelings

Indifferent mood, with neither joy nor sadness

No attachment or interest in the baby

Inertia

Hopelessness or thoughts of harming self or baby

of depression in the perinatal period is $11.5 \%$

\section{Somatic complaints}

Presentation of vague and continuous body symptoms that persist for weeks, including headaches, body pains, feeling of racing heart, constant fatigue

Active anger and resentment of the baby

Constant irritability and negative mood

One of every 7 to 10 pregnant women and 1 of every 5 to 8 postpartum women develop a depressive disorder, which is more than a half million women each year. The mean rate of depression during the perinatal period is $11.5 \% .^{3}$

Perinatal depression is thought to be the result of a complex interaction involving genetics, epigenetics, the neuroendocrine hypothalamicpituitary-adrenal axis, and environmental and social factors. No race or socioeconomic group is spared. ${ }^{4,5}$ Some women are more sensitive to changes in their reproductive hormone levels during pregnancy and after delivery, which may make them more susceptible to perinatal depression. Some may also have an unrecognized underlying mood disorder. ${ }^{2}$

Risk factors for perinatal depression include:

- A history of depressive, bipolar, or anxiety disorders

- A family history of depressive disorders or perinatal disorders

- An unwanted or teenage pregnancy

- A multiple birth

- A difficult or traumatic pregnancy or birth

- An ongoing health problem with the baby

- A lack of social support with low socioeconomic status and financial difficulties

- A history of physical or sexual abuse

- A diagnosis of substance abuse disorder., ${ }^{3,6-8}$

- American Indian/Alaska and Hawaii Native heritage; these groups have a 30\% higher incidence of perinatal depression.

Of note, other perinatal mental health conditions such as anxiety disorders, bipolar spectrum disorder, or postpartum psychosis may also occur. Perinatal anxiety disorders are common and can frequently coexist with depressive disorders. ${ }^{9}$ In patients with pre-existing bipolar disorder, depressive, hypomanic, and manic episodes can occur, especially in the setting of sleep deprivation. ${ }^{2}$

Postpartum psychosis is characterized by a delirium-like presentation with disorganized behavior and psychotic symptoms and is considered a medical emergency, though it is a rare event. It may also, in rare cases, be accompanied by hallucinations that tell the woman to harm herself or her baby. ${ }^{10}$

\section{SERIOUS CONSEQUENCES IF UNTREATED}

Untreated perinatal depression has serious consequences for mothers, their children and families, and society as a whole. During pregnancy, untreated depression is associated with a higher incidence of preterm delivery, preeclampsia, low birth weight, behavior disturbances in the baby at birth, and maternal suicide. ${ }^{11,12}$

Untreated depression during the postpartum period also has repercussions for both the mother and her baby. For the mother, it can lead to intense sadness, marked anxiety, and 
a lack of interest in life and the child, often resulting in poor or absent maternal bonding with the infant. It is also associated with failure to initiate breastfeeding or a shortened duration of breastfeeding. ${ }^{13}$

When perinatal depression is severe, the mother's symptoms can progress to ideation of self-harm or of harming the infant, or at its worst, suicide or infanticide. Suicide is the second-leading cause of death for women in the postpartum period, leading to $20 \%$ of deaths during the first year after birth. ${ }^{14,15}$ Thoughts of harming the baby occur in $41 \%$ of depressed mothers vs $7 \%$ of controls. ${ }^{16} \mathrm{Al}$ though infanticide is a rare event, at least 1 case occurs every 3 days in this country. ${ }^{17}$

The absence of maternal bonding can have a significant impact on the infant's development. Numerous controlled studies have shown that children born to mothers with untreated postpartum mood disorders are more likely to have impaired cognitive, behavioral, and emotional development and delayed social and communication skills. ${ }^{18-21}$ The problem then becomes a serious public health issue, with consequences spanning several generations.

\section{SCREENING IS KEY TO DIAGNOSING PERINATAL DEPRESSION}

Perinatal depression is frequently missed because many of the signs, including acute and chronic stress, lack of sleep, and hormone swings, are present in all pregnant women. In addition, new mothers may not admit to having symptoms because they feel an overwhelming sense of shame and embarrassment about being "less of a mother" than they believe they should be. ${ }^{22}$ Furthermore, family members may not understand that their partner's or relative's behavior constitutes a clinical depression that requires treatment.

Primary care clinicians can dramatically increase the rate of detection and diagnosis by screening pregnant and postpartum patients for mood and anxiety disorders. Trials in the United States have concluded that screening improves outcomes in the depressed mother. ${ }^{23,24}$ Therefore, screening is recommended for all women in the perinatal period by a number of organizations, including the US Preventive Services Task Force (USPSTF), ${ }^{25-27}$ the Amer- ican College of Obstetricians and Gynecologists, the American Psychiatric Association, and the American Academy of Pediatrics.

One of the simplest and most reliable screening tools is the Edinburgh Postnatal Depression Scale (EPDS). ${ }^{28}$ The EPDS is a cross-culturally validated 10-question form that a woman can complete in 2 to 3 minutes in a waiting room, online, or with a clinician. Sensitivity and specificity range from $70 \%$ to $88 \%,{ }^{29}$ and studies have found that the EPDS is twice as effective as a clinician's interview in detecting depression. ${ }^{30}$

The Patient Health Questionnaire (PHQ$9)^{31}$ is also an effective tool for screening, but it does not contain questions about anxiety as the EPDS does.

It is also important to screen for intimate partner violence, which may contribute to or cause the patient's depression.

Pregnant women should be screened at the initial prenatal visit and again in the last trimester. Postpartum mothers should be screened during the 6-week postpartum visit and again by the primary care physician who takes over the care of the patient after the final postpartum visit. Birth classes, prenatal visits, postpartum checks, and monthly well-baby visits all provide easy points of contact with a woman before and after she gives birth. ${ }^{24,25}$ Screening is now a covered medical expense during a medical visit, both under the Affordable Care Act and with private insurance.

Particular attention should be paid to women of color or those from lower socioeconomic groups since their incidence of perinatal depression is significantly higher, and inadequate research has been done to study effective remedies in these groups. Women from minority groups and women from lower socioeconomic communities suffer disproportionately from these failures to diagnose and treat. ${ }^{32}$

Once a patient screens positive, she should undergo further clinical evaluation to make the diagnosis of depression. It is important for screening programs to include follow-up and support systems. ${ }^{25}$ Additionally, all women diagnosed with perinatal depression should be counseled that their condition is a medical illness, that there are good treatments, and that they are "no less of a mother" for experiencing it.

\section{Suicide is the second-leading cause of death for women in the postpartum period}




\section{BIOMARKERS PREDICT}

Promising research is focusing on the use of biomarkers to predict which patients will develop perinatal depression. One set of studies identified 2 epigenetically modified genes that can predict with $80 \%$ accuracy if a woman will develop depression in the immediate postpartum period. ${ }^{33,34}$ While further validation is needed, these studies indicate that in the future, women may be able to be screened for postpartum depression while still pregnant.

\section{PERINATAL DEPRESSION} CAN BE PREVENTED IN SOME PATIENTS

The USPSTF reviewed 50 scientific studies that met their rigorous methodologic criteria and found good evidence that counseling interventions during pregnancy and the postpartum period are effective in preventing perinatal depression in some women. ${ }^{35,36}$ Interventions were associated with a 39\% decrease in the likelihood of perinatal depression in women who were at risk for depression and had been involved in therapeutic interventions before the onset of depression. Women who received counseling had one of

All women should be screened for depression before and after they give birth the following risk factors: a personal or family history of depression, a history of physical or sexual abuse, socioeconomic insecurity, or recent negative life events.

Two specific treatments had the greatest effect: interpersonal therapy and cognitive behavioral therapy, in either an individual or a group setting. Counseling sessions averaged 8 weeks in duration. The USPSTF concluded that counseling interventions can be effective in preventing perinatal depression in pregnant or postpartum women with an elevated risk of perinatal depression. ${ }^{34}$

\section{WHAT IS THE TREATMENT FOR PERINATAL DEPRESSION?}

Although screening is important for detecting perinatal depression, screening itself is not sufficient to improve outcomes unless mechanisms are in place to respond to a positive screen, and treatment and follow-up occur. Individual psychotherapy and other modalities - such as postpartum support groups, family therapy, remote video conferencing, phone check-ins, and home visits with trained men-

tal health providers-are often effective in treating these disorders without the use of medication. . $^{5,2436}$

Primary care and internal medicine hospital departments and outpatient practices have had success in treating these patients using an integrated care model developed in a collaboration between the Health Resources and Services Administration and the Substance Abuse and Mental Health Services Administration. ${ }^{37}$

Despite progress in using nonpharmacologic modalities to treat perinatal depression, medication is sometimes necessary. In current practice, many women are often advised to stop taking all psychotropic medications when they become pregnant or breastfeed, but research has shown that a more nuanced and tailored approach is necessary. Many psychiatric medications have been shown to pose a low risk during pregnancy and lactation. Many reproductive psychiatrists have found that, for some women, taking medication is more advantageous to the mother's health and to the child's development than not taking it, given the data on the effects of untreated depression on pregnancy and child development. ${ }^{13}$

Thus, when a woman needs to consider taking medication during pregnancy and lactation, it is best to refer her to a psychiatrist or reproductive psychiatrist for care during the perinatal period. At this time, whether to take medication is a decision that the patient and her treating physicians should make after considering her unique circumstances and psychiatric history. ${ }^{13,38,39}$

Brexanolone, a new parenteral medication, was approved by the US Food and Drug Administration in March 2019 for moderate to severe depression. ${ }^{40}$ Brexanolone has been studied in 2 multicenter, randomized, placebocontrolled trials ${ }^{41}$ and can produce rapid and in some cases immediate symptom relief, including reducing acute suicidal ideation. At this point, the medication is infused under supervision over 3 days. Research continues to focus on developing an oral preparation that would allow a more practical and less costly route of administration. ${ }^{40}$

Dedication: This article is dedicated to Paul and Margaret Burke. 


\section{REFERENCES}

1. Gavin NI, Gaynes BN, Lohr KN, Meltzer-Brody S, Gartlehner G, Swinson T. Perinatal depression: a systematic review of prevalence and incidence. Obstet Gynecol 2005; 106(5 pt 1):1071-1083.

doi:10.1097/01.AOG.0000183597.31630.db

2. Henshaw C. Mood disturbance in the early puerperium: a review. Arch Wo mens Ment Health 2003; 6(suppl 2):S33-S42. doi:10.1007/s00737-003-0004-x

3. Ko JY, Rockhill KM, Tong VT, Morrow B, Farr SL. Trends in postpartum depressive symptoms-27 states, 2004, 2008, and 2012. MMWR Morb Mortal Wkly Rep 2017; 66(6):153-158. doi:10.15585/mmwr.mm6606a1

4. Couto TC, Brancaglion MY, Alvim-Soares A, et al. Postpartum depression: a systematic review of the genetics involved. World J Psychiatry 2015; 5(1):103-111. doi:10.5498/wjp.v5.i1.103

5. Meltzer-Brody S. New insights into perinatal depression: pathogenesis and treatment during pregnancy and postpartum. Dialogues Clin Neurosci 2011; 13(1):89-100. pmid:21485749

6. O'Hara MW, Swain AM. Rates and risk of postpartum depression-a meta-analysis. Int Rev Psychiatry 1996; 8:37-54.

7. Jeong HG, Lim JS, Lee MS, Kim SH, Jung IK, Joe SH. The association of psychosocial factors and obstetric history with depression in pregnant women: focus on the role of emotional support. Gen Hosp Psychiatry 2013; 35(4):354-358. doi:10.1016/j.genhosppsych.2013.02.009

8. Biaggi A, Conroy S, Pawlby S, Pariante CM. Identifying the women at risk of antenatal anxiety and depression: a systematic review. J Affect Disord 2016; 191:62-77. doi:10.1016/j.jad.2015.11.014

9. Fairbrother N, Young AH, Janssen P, Antony MM, Tucker E. Depression and anxiety during the perinatal period. BMC Psychiatry 2015; 15:206. doi:10.1186/s12888-015-0526-6

10. Bergink V, Rasgon N, Wisner KL. Postpartum psychosis: madness, mania and melancholia in motherhood. Am J Psychiatry 2016; 173(12):1179 1188. doi:10.1176/appi.ajp.2016.16040454

11. Jarde A, Morais M, Kingston D, et al. Neonatal outcomes in women with untreated antenatal depression compared with women without depression: a systematic review and meta-analysis. JAMA Psychiatry 2016; 73(8):826-837. doi:10.1001/jamapsychiatry.2016.0934

12. Field T, Diego M, Hernandez-Reif M. Prenatal depression effects and interventions: a review. Infant Behav Dev 2010; 33(4):409-418. doi:10.1016/j.infbeh.2010.04.005

13. Payne JL. Psychopharmacology in pregnancy and breastfeeding. Psychiatr Clin North Am 2017; 40(2):217-238. doi:10.1016/j.psc.2017.01.001

14. Lindahl V, Pearson JL, Colpe L. Prevalence of suicidality during pregnancy and the postpartum. Arch Womens Ment Health 2005; 8(2):77-87. doi:10.1007/s00737-005-0080-1

15. Orsolini L, Valchera A, Vecchiotti R, et al. Suicide during perinatal period: epidemiology, risk factors, and clinical correlates. Front Psychiatry 2016; 7:138. doi:10.3389/fpsyt.2016.00138

16. Jennings KD, Ross S, Popper S, Elmore $\mathbf{M}$. Thoughts of harming infants in depressed and nondepressed mothers. J Affect Disord 1999; 54(1-2):2128. doi:10.1016/s0165-0327(98)00185-2

17. Meyer $\mathrm{CL}$, Oberman $\mathbf{M}$. Mothers who kill their children: understanding the acts of moms from Susan Smith to the "prom mom." New York, NY: NYU Press; 2001.

18. Grace SL, Evindar A, Stewart DE. The effect of postpartum depression on child cognitive development and behavior: a review and critical analysis of the literature. Arch Womens Ment Health 2003; 6(4):263-274. doi:10.1007/s00737-003-0024-6

19. Pilowsky DJ, Wickramaratne P, Talati A, et al. Children of depressed mothers 1 year after the initiation of maternal treatment: findings from the STAR*D-Child Study. Am J Psychiatry 2008; 165(9):1136-1147. doi:10.1176/appi.ajp.2008.07081286

20. Dunkel Schetter C, Tanner L. Anxiety, depression and stress in pregnancy: implications for mothers, children, research, and practice. Curr Opin Psychiatry 2012; 25(2):141-148. doi:10.1097/YCO.0b013e3283503680

21. Mughal MK, Giallo R, Arnold PD, et al. Trajectories of maternal distress and risk of child developmental delays: findings from the All Our Families (AOF) pregnancy cohort. J Affect Disord 2019; 248:1-12. doi:10.1016/j.jad.2018.12.132

22. Edwards $\mathbf{E}$, Timmons $\mathbf{S}$. A qualitative study of stigma among women suffering postnatal illness. J Mental Health 2009; 14(5):471-481.

23. Leung SS, Leung C, Lam TH, et al. Outcome of a postnatal depression screening programme using the Edinburgh Postnatal Depression Scale: a randomized controlled trial. J Public Health (Oxf) 2011; 33(2):292-301. doi:10.1093/pubmed/fdq075

24. Yawn BP, Olson AL, Bertram S, Pace W, Wollan P, Dietrich AJ. Postpartum depression: screening, diagnosis, and management programs 2000 through 2010. Depress Res Treat 2012; 2012:363964. doi:10.1155/2012/363964

25. US Preventive Services Task Force. Final recommendation statement: depression in adults: screening. http://www.uspreventiveservicestaskforce. org/Page/Document/RecommendationStatementFinal/depression-inadults-screening1. Accessed April 4, 2020.

26. Siu AL, US Preventive Services Task Force, Bibbins-Domingo K, et al. Screening for depression in adults: US Preventive Services Task Force recommendation statement. JAMA 2016; 315(4):380-387. doi:10.1001/jama.2015.18392

27. O'Connor E, Rossom RC, Henninger M, Groom HC, Burda BU. Primary care screening for and treatment of depression in pregnant and postpartum women: evidence report and systematic review for the US Preventive Services Task Force. JAMA 2016; 315(4):388-406. doi:10.1001/jama.2015.18948

28. Cox JL, Holden JM, Sagovsky R. Detection of postnatal depression. Development of the 10-item Edinburgh Postnatal Depression Scale. Br J Psychiatry 1987; 150:782-786. doi:10.1192/bjp.150.6.782

29. Cox JL, Chapman G, Murray D, Jones B. Validation of the Edinburgh Postnatal Depression Scale (EPDS) in non-postnatal women. J Affect Disord 1996; 39(3):185-189. doi:10.1016/0165-0327(96)00008-0

30. Evins GG, Theofrastous JP, Galvin SL. Postpartum depression: a comparison of screening and routine clinical evaluation. Am J Obstet Gynecol 2000; 182(5):1080-1082. doi:10.1067/mob.2000.105409

31. Kroenke K, Spitzer RL, Williams JB. The PHQ-9: validity of a brief depression severity measure. J Gen Intern Med 2001; 16(9):606-613. doi:10.1046/j.1525-1497.2001.016009606.x

32. Kozhimannil KB, Trinacty CM, Busch A, Huskamp HA, Adams AS. Racial and ethnic disparities in postpartum depression care among low-income women. Psychiatr Serv 2011; 62(6):619-625. doi:10.1176/ps.62.6.pss6206_0619

33. Guintivano J, Arad M, Gould TD, Payne JL, Kaminsky ZA. Antenatal prediction of postpartum depression with blood DNA methylation biomarkers. Mol Psychiatry 2014; 19(5):560-567. doi:10.1038/mp.2013.62

34. Osborne L, Clive M, Kimmel M, et al. Replication of epigenetic postpartum depression biomarkers and variation with hormone levels. Neuropsychopharmacology 2016; 41(6):1648-1658. doi:10.1038/npp.2015.333

35. US Preventive Services Task Force; Curry SJ, Krist AH, Owens DK, et al. Interventions to prevent perinatal depression. US Preventive Services Task Force recommendation statement. JAMA 2019; 321(6):580-587. doi:10.1001/jama.2019.0007

36. Dennis CL, Hodnett E, Kenton L, et al. Effect of peer support on prevention of postnatal depression among high risk women: multisite randomised controlled trial. BMJ 2009; 338:a3064. doi:10.1136/bmj.a3064

37. SAMHSA-HRSA Center for Integrated Health Solutions. Behavioral health in primary care. https://www.integration.samhsa.gov/integrated-caremodels/behavioral-health-in-primary-care. Accessed April 4, 2020.

38. Wisner KL, Gelenberg AJ, Leonard H, Zarin D, Frank E. Pharmacologic treatment of depression during pregnancy. JAMA 1999; 282(13):12641269. doi:10.1001/jama.282.13.1264

39. Yonkers KA, Wisner KL, Steward DE, et al. The management of depression during pregnancy: a report from the American Psychiatric Association and the American College of Obstetricians and Gynecologists. Obstet Gynecol 2009; 114(3):703-713. doi:10.1097/AOG.0b013e3181ba0632

40. US Food and Drug Administration. FDA approves first treatment for postpartum depression. https://www.fda.gov/NewsEvents/Newsroom/PressAnnouncements/ucm633919.htm. Accessed April 4, 2020.

41. Meltzer-Brody S, Colquhoun $\mathbf{H}$, Riesenberg R, et al. Brexanolone injection in post-partum depression: two multicentre, double-blind, randomised, placebo-controlled, phase 3 trials. Lancet 2018; 392(10152):1058-1070. doi:10.1016/S0140-6736(18)31551-4

Address: Maureen Sayres Van Niel, MD, President, APA Women's Caucus, American Psychiatric Association, 25 York Road, Waban, MA 02468; maureen.vannie/@gmail.com 